\title{
Development and Trend of Condition Monitoring and Fault Diagnosis of multi- sensors information fusion for Rolling Bearings, A Review
}

\author{
Zhihe Duan ${ }^{1}$, Tonghai $\mathrm{Wu}^{1, *}$, Shuaiwei Guo ${ }^{1}$, Tao Shao ${ }^{1}$, Reza Malekian,,* Zhixiong Li3 \\ ${ }^{1}$ Key Laboratory of Education Ministry for Modern Design and Rotor-Bearing System, School of Mechanical \\ Engineering, Xi'an Jiaotong University, Xi' an 710001, China \\ ${ }^{2}$ Department of Electrical, Electronic \& Computer Engineering, University of Pretoria, Pretoria 0002, South \\ ${ }^{3}$ School of Mechatronics Engineering, China University of Mining \& Technology, Xuzhou 221110, China \\ Zhihe Duan: duanzh@stu.xjtu.edu.cn, Tonghai Wu: wt_h@163.com, Shuaiwei Guo: 1820807893@qq.com, Tao \\ Shao: shaotao9192@stu.xjtu.edu.cn, Reza Malekian: reza.malekian@ieee.org, Zhixiong Li: \\ zhixiong.li@ieee.org
}

* Correspondence: reza.malekian@ieee.org Tel.: +27124204305

\begin{abstract}
A rolling bearing is an essential component of a rotating mechanical transmission system. Its performance and quality directly affects the life and reliability of machinery. Bearings' performance and reliability need high requirements because of a more complex and poor working conditions of bearings. A bearing with high reliability reduces equipment operation accidents, equipment maintenance costs and achieves condition-based maintenance. First in this paper, the development of technology of the main individual physical condition monitoring and fault diagnosis of rolling bearings are introduced, then the fault diagnosis technology of multi- sensors information fusion is introduced, finally the advantages, disadvantages and trends developed in the future of the detection main individual physics technology and multi-sensors information fusion technology are summarized. This paper is expected to provide the necessary basis for the follow-up study of the fault diagnosis of rolling bearings and a foundational knowledge for researchers about rolling bearings.
\end{abstract}

Keywords: Rolling bearings; detection technology; condition monitoring; fault diagnosis

\section{Introduction}

A rolling bearing is an indispensable part of the rotating machinery. It has been widely used in aerospace, navigation, machine tools and other fields. The performance and quality of the rolling bearing directly influences the service life and reliability of the aviation engine as the key part of the areocraft.With the development of rolling bearings in the theoretical research, structural design, manufacturing process and other aspects of the bearings, the performance and reliability of bearings have been greatly improved. At the same time, with the rapid development of modern industrial technology, the engine thrust weight ratio and power are also growing, and the bearing working conditions are becoming complex. Therefore the higher requirements are put on the bearing performance and reliability[1]. According to statistics, of the around 4 billion bearings used in the world every year, about $9.5 \%$ are ahead of time to replace in safety considerations, and about $0.5 \%$ fail because the bearing safety criteria [2]. In the routine maintenance of aircraft, engine maintenance and replacement costs are very large. The maintenance costs accounts for more than 60\% [3], so keeping the higher reliability of rolling bearings has a significant effect to reduce equipment accidents, the maintenance cost, and achieve condition based maintenance.

The higher reliability of a rolling bearing depends on a higher reliability of the bearing itself and the condition monitoring and fault diagnosis technology in real time. At present, the technology of fault diagnosis has been developed for many years, and achieved many results. In the industrial revolution, the fault diagnosis technology appeared; In 60s, briefly detection technology applied on material properties based on reliability theory ; In 80s, a mathematical model for fault diagnos had been emerged, then artificial intelligent diagnosis technology developed; Since the end of 90s, based on local area network and Internet network, resource sharing 
and remote diagnosis could be carried out to expand the more monitoring parameters and describe the more comprehensive equipment operation process [4]. In this paper, the condition monitoring and fault diagnosis technology of rolling bearings are introduced first as the main topic of importance, then we look forward to the current or future development trend of state monitoring and fault diagnosis technology, so as to provide the necessary basis for the follow-up study on the fault diagnosis of rolling bearings and a foundational knowledge for researchers about rolling bearings.

Section 1 of this paper briefly introduces the significance and necessity of the condition monitoring and fault diagnosis of rolling bearings. Section 2 discusses the development of the main individual physical monitoring technology for rolling bearing condition monitoring. Section 3 introduces the current development of multi-sensors information fusion and finally summarizes the shortcomings and development trend of the main individual physical monitoring technology and multi-sensors information fusion technology.

\section{The development of the main individual physical monitoring technology}

The initial spall-like on the contact surface of the rolling bearing produces an abnormal signal, which indicates the bearing failed. In spite of the initial damage on the surface of the bearings, which means the wear increases and the operation condition fluctuates, the bearings may be used until the friction-pair contact surface is completely destroyed. Due to the bearing being stuck or the excessive dynamic load and broken parts, the machine will stop running [5]. These indicate that the potential disaster will cause the excessive maintenance costs, bad operation, a non-normal shutdown, and even a threat to life, so the preventive maintenance (PM) appears. PM can be used to reduce the non-normal shutdown caused by bearing fatigue. According to the calculation of rolling bearing fatigue life, the periodic contact surface wear phenomena or bearing fatigue data, the cycle of machine maintenance can be predicted. Therefore, in this period the rolling bearings can be inspected and replaced. As known, except for the cost of replacement equipment, production and tax losses, PM will replace the normal working bearings before the failure of the bearing, so the condition based maintenance (CBM) appears. The CBM can be realized by monitoring the condition of the bearing, and obtaining the information of the possible failure of the bearing, and the knowledge of the prediction time and the effective performance of the bearing [6,7]. At present, according to the different mechanism of monitoring condition and fault diagnosis technology, the technology mainly includes parameters like vibration, acoustic emission, oil analysis and temperature detection.

\subsection{Vibration}

Vibration is the most widely used technology to evaluate the operation and the bearing condition. Even if the bearing is deteriorating and close to end or a new bearing, vibration is an available way. Vibration can be used to infer the machine parts condition. The processes includes data acquisition, feature extraction, pattern recognition and decision analysis [8], as shown in the Fig. 1. We will not discuss the data acquisition in this paper.

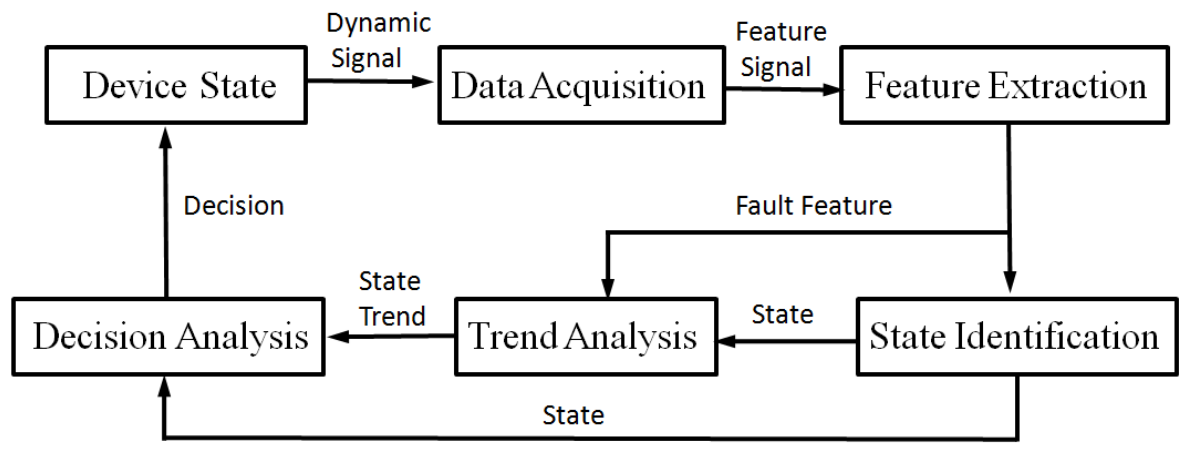

Fig. 1 The process of fault diagnosis

The vibration signals are obtained from the vibration test equipment, which is fixed or portable.The sensors are divided into displacement sensors, speed sensors and acceleration sensors. The choice of sensor depends on its application. A displacement sensor is an electric eddy current sensor, which is a non-contact measurement and generally used to measure the orbit or some extreme conditions; the acceleration sensor is the more general measurement method. The corresponding frequency can reach $20 \mathrm{k} \mathrm{Hz}$; the application of speed sensor is between the other two kind sensors and limited to the low frequency response.

The point of the analysis of vibration signals of rolling bearings in the early stages was to distinguish the characteristics of the time and frequency domain and finally to identify the fault diagnosis. Kinsky and Sturm [9] had established a new method named normalized zero condition, which is more suitable for fault diagnosis 
than the direct application of the characteristic of the vibration signal because it does not depend on time. Mechefske and Mathew[10] adopted the parameter's autoregressive model to get the frequency spectrum, and obtained parametric spectra index such as arithmetic mean, geometric mean value, the root mean square of matched filter, root mean square of difference spectrum, spectral difference square. The tests results showed that this method can identify the bearing condition better compared with the traditional fast Fourier transform spectrum method, especially in the low speed of the bearing. Then [11] spectrum estimation based on FFT technology was compared with the autoregressive model to prove that analysis of short-time signal based on autoregressive model method is very effective. Martin and Honarvar[12] carried out the rolling bearings fault diagnosis based on the time domain normalized skewness and kurtosis parameters and had significant results. This method is a low cost method for maintenance and quality control. Statistical parameters of wave factors and kurtosis were used to perform fault diagnose of rolling bearings by Heng and Nor[13]. In addition the results were compared with results affected by parameters which obey the beta distribution. Tests results showed that wave factor and kurtosis have an accurate judgment with the bearing condition, but the beta distribution parameters have no optimization effect on the bearings' fault diagnosis. Mori et al.[14] adopted discrete wavelet transform to extract the time-frequency domain characteristic parameters of ball bearing in the operation process to predict spall-like damage. The experimental results showed that wavelet coefficients had a good reaction when the ball is through the pre-palling position, so it can be used to predict the ball bearing fault. $\mathrm{Li}$ and $\mathrm{Wu}[15]$ had developed a simultaneous segmentation and template learning machine used for on-line identification of fault-sensitive resonance. The principle sequence for each burst sequence related to defects are divided into several sub sequences, and then the autoregressive moving average model was used to deal with the dynamic sub-sequences data separately, and the minimum distance classifier based on the results fed back identified fault diagnosis. The matched filter was used for calculating signal energy contribution of fault sensitive resonance to evaluate the damage degree of bearing. The results show that the method has a good effect.

After the development of time and frequency domain characteristics into a certain stage, the relevant statistical parameters are introduced into the vibration analysis. Dron et al.[16] compared the performance of the different parametric autoregressive spectral analysis methods with the traditional spectral analysis methods' for bearings' fault diagnosis. The autoregressive model along with Bugh algorithm and Akaike information criterion was retained. Tests results showed that the parametric method has a high resolution, and can find the fault earlier, especially in the similar fault characteristic frequency. However, due to the complexity of the algorithm, the method cannot completely replace the traditional spectral ways, but it can enhance the effectiveness of the traditional methods. Liu et al. [17] proposed a new method named Matching Pursuit Time Frequency Atoms to analyze and the extract features of the vibration signal for the fault diagnosis of rolling bearings. This approach utilized not only the temporal spectral but also the scale characteristic of the vibration generated due to the presence of a defect for the fault detection. The test results showed that this method can provide stronger signal-noise ratio in early fault period of rolling bearing comparing with the continuous wavelet transform and Hilbert transform envelope technique, which has a higher sensitivity and reliability. Samanta and AI-Balushi[18] extracted the vibration signal features such as root mean square, variance, skewness, kurtosis and normalized sixth center distance as the input of the neural network to realize rotating machinery rolling bearing fault diagnosis. High pass/band pass filtration, envelope detection and wavelet transform technology for signal preprocessing showed no difference. Test results demonstrated that the neural network can realize the fault diagnosis of the bearing, and have a good application prospect in the bearing of online condition monitoring and fault diagnosis. Lou and Loparo[19] used wavelet transform and adaptive neural fuzzy inference system to realize inner race fault diagnosis of ball bearings. By comparing with the Euclidean vector distance method and correlation coefficient method, experimental results showed that the reliability of this method is higher with respect to identifying the different failure conditions. Mohanty and $\operatorname{Kar}[20]$ proposed a new statistical parameter D-stat for rolling bearing fault diagnosis, which required less computation compared to the mature technology, discrete wavelet transform. Tests results showed that the method has a better effect on rolling bearings' fault diagnosis. Its main advantage was that it was affected less by time lag, but in the Kolmogorov \& Smirnov test data loss was found, and the phenomenon was more obvious in the center than the tail. Purushotham et al.[21] adopted Discrete Wavelet Transform (DWT) to determine the inner ring's, outer ring's, roller element's and their whole system's fault diagnoses. Tests results showed that DWT for single point and multi-point ball bearing fault diagnosis is effective comparing with the characteristics extracting and spectrum analysis by wavelet transform. At the same time, the authors established a hidden 
Markov model classifier by inputting the Mel frequency complex spectrum coefficients. Experimental results showed that the model training in minutes has a fault identification rate about $99 \%$, as Fig 2. shows.

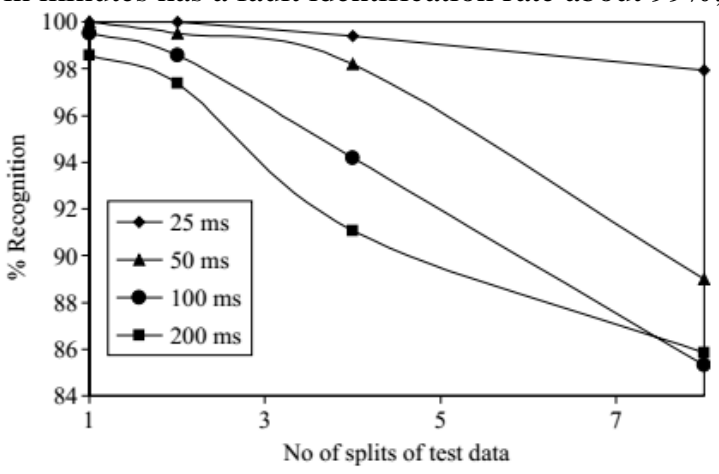

Fig 2. Pattern recognition curve for various window sizes[21]

Randall [22] proposed a new de-noising technique and a Discrete Random Separation (DRS) technology which were applied in the fault diagnosis of the gear box in Sea Hawk helicopters of US Navy. The experimental results showed that the DRS technology is more effective than the adaptive noise cancellation technique, especially getting the spectrum in the lower frequency domain. Then Sawalhi and Randall[23-24] extended the techniques to the application of rolling bearing's inner ring and outer ring fault diagnosis. Cheng et al.[25] proposed a new feature extraction method to enhance the ability for the adaptive model to deal with the non-stationary signal of rolling bearings. Firstly, the non-stationary was broken into a number of intrinsic mode function components which are stationary by using the empirical mode decomposition. Then the auto regressive model was applied to deal with each section of the processing. Finally, a condition judgment was made by the Mahalanobis distance criterion function. The test results showed that this method can effectively be applied to the fault diagnosis of rolling bearings. Hao and Chu [26] put forward a new method of morphological wavelet. This method made the smoothing about the pulse characteristics and noise at the same time based on morphological wavelet theory, then extracted the features of rolling bearing fault signal. The experimental results showed that the method is more effective than the traditional wavelet transform and morphological wavelet transform, and suitable for the on-line condition monitoring and fault diagnosis of rotating machinery rolling bearings. Zhang et al.[27] proposed a new vibration signal processing method based on local optimization wavelet packet. The optimal basis of this method was determined by the ability of classification. Feature extraction and local decision were realized by Bayesian inference, and the weighted average of the data was used for the fault diagnosis. Test results showed that the method has a high accuracy. Khemili and Chouchane [28] pointed out that the difficulty in fault diagnosis of rolling bearings is the noise. Therefore in order to enhance the vibration signal-to-noise ratio to effectively judge bearing state, the authors adopted the adaptive noise cancellation and the adaptive self-tuning filter to deal with the vibration signal of the bearing. The test results showed that the adaptive filter has a higher signal-to-noise ratio. Abbasion et al. [29] did de-noising and feature extraction of the vibration signal for rolling bearing fault classification by utilizing discrete Mayer wavelet and later the Weibull negative log-likelihood function, and the features were input into the Support Vector Machine (SVM). Test results showed that the accuracy of SVM for the fault diagnosis under small samples is $100 \%$. Yuan et al.[30] set up Geronimo Hardin's and Masssopust's adaptive multi wavelet library based on similarity scale conversion for the complex and non-stationary characteristics of the rolling bearing vibration signal in the early stage, then realized the fault detection by the optimization of kurtosis maximization principle. Experimental results showed that the method is more effective than the original GHM multi wavelet, Db6scaler wavelet, Fourier transform, spectral kurtosis and other algorithms to detect the excitation characteristics of vibration signals. Wang et al. [31] presented a method of dual tree complex wavelet transform to enhance the fault characteristics of some special equipment. This method compared with the second-generation wavelet transform and empirical mode decomposition could reduce spectrum aliasing. At the same time, dual-tree complex wavelet transform with NeighCoeff shrinkage was used to improve the signal--noise ratio, and had a higher efficiency. Experimental results showed that this technique is robust, and its performance is better than second generation wavelet transform and kurtogram fast. And the method is suitable for on-line condition monitoring and fault diagnosis because of its robustness and high efficiency. Wang et al. [32] proposed an adaptive time-frequency algorithm based on Calman's smoothing method. It obtained the time-frequency spectrum and a higher time-frequency spectrum resolution precisely which was 
compared with the method of short-time Fourier transform, non parametric Wigner-Ville distribution, Choi-Williams distribution and wavelet transform. Then the radial basis function neural network was used to classify the bearing state. The test results showed that the method can effectively diagnose the bearing fault automatically and accurately. Wang et al.[33] extracted the oscillator and two-dimensional approximate entropy in a large periodic signal from a chaotic state of vibration signal using a chaotic oscillator. The test results showed that the features of the machine is very sensitive to weak signals, the two-dimensional approximate entropy can effectively identify faults, and the method has a high accuracy. Hong and Liang [34] adopted the Lempel-Ziv complexity value to judge the single point fault severity of bearing. The method first adopted the continuous wavelet transform to obtain where the best scale of the fault resides and eliminate the interferences of noise and irrelevant signal components, then calculates the Lempel-Ziv complexity value. The test results showed that the method can effectively detect the single point failure of rolling bearings, and the change of the normalized Lempel-Ziv complexity value can indicate the increasing trend of the number of faults. Lei et al.[35] pointed out krutogram has the superiority in the monitoring and characterization of transient signal, but it has a bad precision affected by the noise to extract transient signal features . The wavelet transform is introduced to improve kurtogram to eliminate noise and match noise characteristics accurately. Test results show that it has a higher accuracy compared to the original kurtogram for fault diagnosis of bearings.

The vibration analysis will provide more reliable parameters to evaluate the rolling bearing state with the improvement to feature extraction techniques. A part of work in recent years about vibration feature extraction techniques is multi-algorithm fusion to improve the efficiency and reliability compared to the original method . Zhou et al.[36] proposed the two order cycle stability analysis to realize feature extraction of the fault in the early stage. This method can restrain the noise and provide higher order statistical parameters and provide more information compared to the traditional spectrum analysis and the envelope analysis method. Slices Spectrum Analysis was used for fault diagnosis of rolling bearings. Test results showed that this method has better reliability and stability. Wang et al. [37] pointed out Scalar Wavelet Thresholding method can extract the vibration characteristics effectively after reducing noise, but it may not be able to obtain some parameters accurately, and it did not consider the effect of neighboring coefficients. Therefore, the authors adopted wavelet de-noising to improve it. The experimental results showed that the improved method has a better performance compared to the traditional method, as Fig 3. shows.

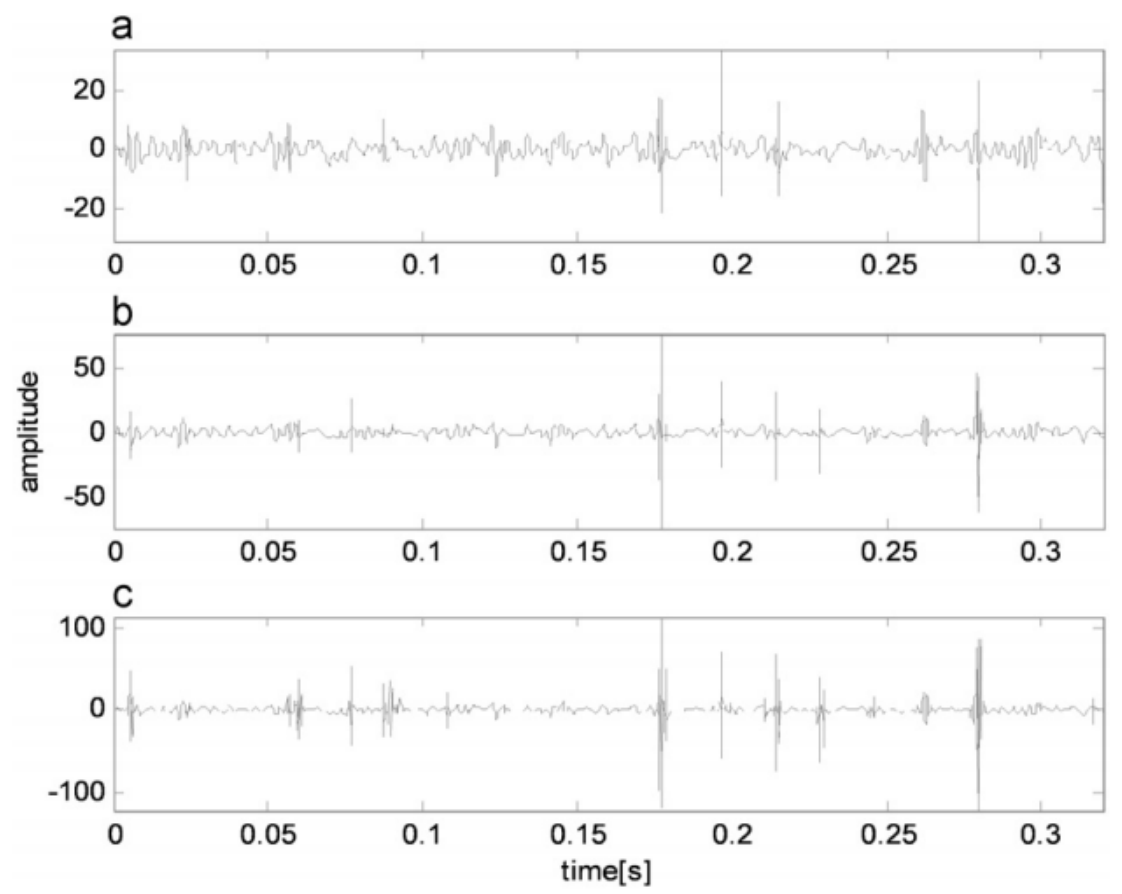

Fig 3. The results of denoising for bearing signal with different methods:(a)D8 wavelet with soft thresholding. (b)GHM multiwavelet with soft thresholding. (c)GHM multiwavelet with NeighCoeff.[37]

Lei et al.[38] summed up the application of empirical mode decomposition in the fault diagnosis of key parts of rotating machinery and equipment, including rolling bearings, gears and motors. Wang et al.[39] extended the application of morphological filter in vibration signal time domain features extraction. First open 
close and close open morphological operator was calculated average weighted to obtain the feature of the vibration, then the geometric structure was optimized, finally the effectiveness of the method was verified by using simulation and test. The results showed that it is effective to extract vibration features. Cui et al. [40] developed a matching pursuit algorithm based on dictionary step-impulse to detect the rolling bearing spalling size. First, the step response into the spalling region and the excitation response out the spalling region is obtained, then the relationship between the responses, spalling size and time interval is calculated. Tests results showed that the method is effective and reliable when the faults are made on the outer ring of the rolling bearing. Wang et al.[41] pointed out that many techniques can't get the correct information under know nothing about the rotation speed, so the authors developed a method named adaptive gear interference fault characteristic order and rotational based on order sideband algorithm to detect the faults of bearing and separate the gear interference to it. Test results showed that this method is effective. Li et al.[42] introduced the reduction dimensionality techniques such as independent component analysis, principal component analysis and singular value decomposition, but these methods had some limitations, so the authors proposed a new method based on generalized $\mathrm{S}$ transform and two-dimensional non-negative matrix factorization method. The generalized $\mathrm{S}$ transform could obtain the satisfying time frequency characteristics. The two-dimensional non-negative matrix factorization could reduce the operation cost and obtain more time frequency characteristic information. Test results showed that the method has a good classification ability. Borghesani et al.[43] pointed out the signal enhancement and analysis fusion technique of rolling bearing fault diagnosis were generally divided into three steps. The first is the order tracking and synchronous averaging with the shaft, the second is synchronous harmonics, and the third is to obtain the squared envelope spectrum. But due to the heterogeneous vibration source of industry scene, the synchronous averaging was not sufficient. To solve the problem, the method of cepstrum pre-whitening is proposed. Experimental results showed that the method performs better compared with the traditional pre-whitening.

Vibration analysis is the most mature technology of rolling bearing condition monitoring and fault diagnosis technology. Vibration analysis extracts features such as time and frequency domain statistical parameters firstly, then contrasts of the characteristic parameters under fault conditions, to obtain the state of rolling bearing; with the increasing demand and development of industrial technology, different kinds of signal acquisition, feature extraction, condition evaluation, decision classification technologies are emerging [44]. The development of vibration analysis is not described overall in this paper, but the technology involved is a common method for analyzing vibration fault diagnosis of rolling bearings.

2.2 Acoustic emission analysis

The frequency response of acoustic emission is higher than vibration's, which will be hundreds of thousand $\mathrm{HZ}$ even more than $1 \mathrm{MHz}$. The typical applications of acoustic emission are composite material spalling, fracture and delamination in rolling bearings. It has an advantage to explore the factors affecting the irregular surface of rolling bearings, so the available acoustic emission method is used to obtain the lubricating condition of the bearing and the relative fault information.

Acoustic emission has been developed for a long time for the condition monitoring and fault diagnosis of rolling bearings. Balderston [45] believed that the installation of equipment in the natural state didn't affect the resonance frequency, although the installation will cause a damping effect. The severity of the fault was directly linked with amplitude resonant frequency based on regular monitoring of the rolling bearing's inner ring, roller element and continuous monitoring in lean condition. It was also the one of the applications of acoustic emission technology in early monitoring of the bearing. Yoshioka et al.[46] found that the acoustic emission technique could detect some bearing faults which could not be detected by the vibration analysis. Caltin[47] believed that acoustic emission mainly applied in unbalance, equipment misalignment, loosening and deformation .The spreading signal of acoustic emission was easy to decay, which was mixed with a large number of instantaneous and random signals, so the detection of object needed to be very close to the location of the detection. Holroyd et al.[48] also proved this point and found that the time to detect the bearing's fault by acoustic emission is earlier than vibration. Bagnoli et al.[49] found that the acoustic emission signal had some obvious characteristics when the bearing fault occurred, and the signal was weak when nothing happened. Vibha et al.[50] made the acoustic emission technology as one of the quality detection tools for the used bearings, and the load is $3 \%$ of rated load of the operation process. Test results showed that under the load condition, whether new or used bearings, the peak-peak value has no change, and the peak value of the used bearing is almost five times of the new bearing. Shiroishi et al.[51] detected the bearing condition under 1200 rpm using acoustic emission and vibration. The test's results about different sizes on the fault of the inner 
ring showed that the acoustic emission technique is not sensitive to the inner fault. Yoshioka et al.[52] detected the fatigue failure of a deep groove ball bearing using vibration and acoustic emission techniques. There were 16 tests designed which continued for nearly 130 hours. Test results showed that acoustic emission features counting point increased rapidly, and after 5 hours, the RMS of vibration changed. Though the features cannot identify the location of the fault, it can reflect the lubrication state of the bearing. In order to distinguish the fault severity, Morhain et al. [53] designed test to divide the threshold stage of acoustic emission counts. Test results show that the acoustic emission signal's maximum amplitude was only linked to rotary speed and was irrelevant to load and fault size. Acoustic emission counts can be used to identify the fault whose length is less than $15 \mathrm{~mm}$, and width is less than $1 \mathrm{~mm}$. Choudhury and Tandon[54] researched the application of acoustic emission technique in the fault diagnosis of rolling bearings. The electric spark machining was adopted to process the fault of a bearing's roller element and inner ring. The tests results showed that ring down counts is sensitive to the rolling element and the inner ring small fault, but it increases to a certain extent with the fault size increasing. The peak value of the AE signal is feasible for fault diagnosis of rolling bearings. Guo and Schwach [55] adopted acoustic emission technology to monitor two kinds of bearing steel surface (free of white layer and white layer) to research influence of a white layer to the service life of mechanical components. Test results showed that the acoustic emission parameters such as energy, RMS and acoustic emission signal amplitude for fatigue-crack occurrence and development are very sensitive, and the steel without a white layer has a significantly longer life. AI-Ghamd and Mba [56] utilized the vibration and acoustic emission for the fault of rolling bearings. Tests results showed that the acoustic emission can obtain the fault information earlier than vibration, and identify the fault size to use to monitor the bearing performance. $\mathrm{Li}$ et al.[57] carried out the accelerated fatigue test of an electric park machine bearing under1600rpm and 167\% of the radial rated load. Vibration and acoustic emission technology are used to monitor the process. Tests results showed that the RMS which is dealt with by an adaptive algorithm is directly linked with the severity of fault. Elforjani and Mba [58] adopted acoustic emission to monitor the fatigue damage of low speed rotating machinery. Test speed is $72 \mathrm{rpm}$ and loads were $4 \mathrm{kN}$ and $8 \mathrm{kN}$. The tests results showed that the acoustic emission's reliability, robustness and sensitivity to detect fatigue damage of the low speed shaft, and its energy level has obvious relationship with the crack expansion. The authors consider that acoustic emission is the first time to apply to the low speed shaft for monitoring. Babak et al. [59] utilized vibration and acoustic emission to monitor the state of the helical gear under different working conditions. The tests proved that the acoustic emission technique is effective for fault detection of the helical gear, and more sensitive in the detection of the gear fault comparing with the vibration. It is the first time to propose the AE RMS has a direct relationship with wear characteristics of the helical gear. Kliundu et al. [60] proposed a new method named cyclic spectral correlation to deal with cyclostationary signal for acoustic emission. Tests results showed that the method by using the same traditional evaluation parameters such as RMS, kurtosis, peak factors compared with the traditional envelope spectrum analysis technology has a higher efficiency, especially in identifying the small fault, as Fig 4. shows.

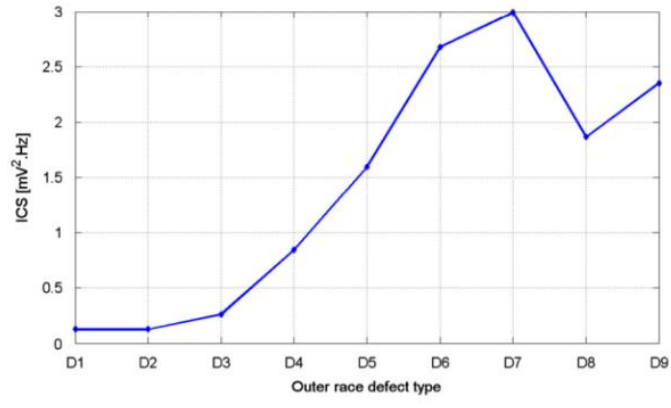

(a)

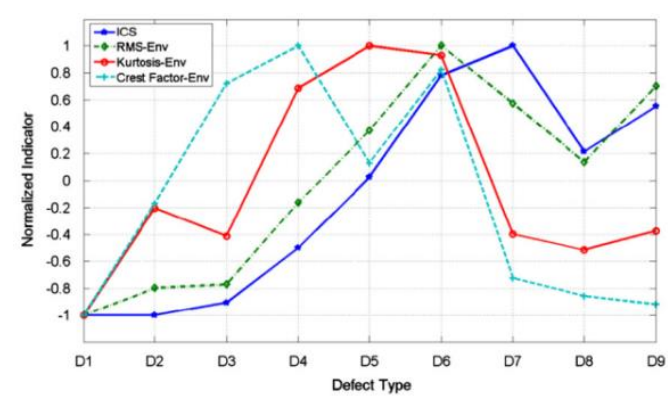

(b)

Fig 4. (a)ICS indicator for varying outer race defect size. (b)Comparison of normalized values from the envelope signals[60].

Gu Et al.[61] used the envelope analysis and discrete wavelet analysis to deal with the acoustic emission signal of the gearbox fault. Tests results showed it has a higher accuracy compared to the traditional envelope analysis. M.Elforjani et al [62] utilized vibration and acoustic emission to monitor the state of the worm gear. Experimental results showed that acoustic emission signal has a higher reliability, robustness and sensitivity than vibration signal. Lu et al. [63] adopted the acoustic emission base on near-filed acoustic holography and gray level co-occurrence matrix for rolling bearing fault diagnosis. The method used Fourier transform of the near-filed acoustic holography to obtain sound field and acoustic respond spectrum under different conditions 
firstly, then gained fault pattern based on gray level co-occurrence matrix, and finally identified the fault state by a multi-class support vector machine based on F-score optimization. Experimental results showed that this method has a higher reliability compared with the traditional acoustic emission signal processing technology, and the validity of the method reached $97.5 \%$. Wang et al[64] used an acoustic emission fault detector to detect the fault of railway bearing. Usually acoustic emission signal processing has three problems: the acoustic emission signal demodulation, Doppler effect elimination and characteristic frequency and amplitude enhancement. The authors adopted the fusion algorithms to solve the above problems, such as a variable-resolution ridge demodulation to extract the characteristic, the dynamic signal resampling method to eliminate the Doppler effect, the average conversion algorithm and piecewise linear trend of separation method to enhance the characteristic frequency and amplitude. Test results showed that it gets the ideal effect. Faris[65] adopted vibration and acoustic emission to analyze the helicopter main gear box bearing. Test load divided into $110 \%$ maximum take-off power, $100 \%$ and $80 \%$ of maximum continuous power; the fault state divided into the state of nature, the primary and serious simulation fault of inner and outer rings. Tests results showed that the acoustic emission technology is effectively to identify the bearing fault, and has advantages compared to vibration on the fault recognition in primary vibration. Sadegh et al[66] utilized acoustic emission to identify the lubrication state of radial bearing. Ten characteristics of AE signal values were used to characterize the lubrication based on the Stribeck curve, and five values of them were chosen as the input of neural network and genetic algorithm. Experimental results showed that it can effectively distinguish the lubrication state of radial bearing. Hase [67] researched radial bearing wear identification by acoustic emission. Acoustic emission is sensitive to the initial crack under high frequency sampling (more than $1 \mathrm{MHz}$ ) ; it has a reaction under intermediate frequency sampling $(0.5 \mathrm{MHz})$ when steel friction pair contact directly ; and bearing has experienced $70 \%$ of a life cycle when the deformation and wear are found under the low frequency (less than or equal to $0.3 \mathrm{MHz}$ when). In the process of identification, characteristics of frequency and amplitude of acoustic emission will change, thus can be used to distinguish the abrasion and wear severity.

Acoustic emission has a higher response frequency compared with vibration, so the acoustic emission can detect weak signals more effectively, but also because of this, the acoustic emission is more susceptible to noise interference, and the development of acoustic emission and vibration methods are similar, such as noise reduction, elimination dimension, feature extraction, classification and decision etc..

\subsection{Oil analysis}

Oil analysis as an effective way to monitor the wear condition of the machine has entered the field of industrial application. It can effectively monitor the wear state and lubrication state of the friction pairs [68]. At present, the technology of ferrography, [69], spectrum, [70] and related physical and chemical analysis [71-72] are used. Some off-line methods that are inefficient and inevitable delays cannot meet the demand of real-time online detection, and online analysis is the inevitable trend of state analysis.

There are two main functions for lubrication oil used in the equipment: one is to reduce the friction between the friction pairs, and the other is to take away the heat caused by the movement between the friction pairs. In the operation process of the equipment, lubricating oil will gradually lead to the decay properties because of oxidation, thermal, and shear effects, so the online oil monitoring sensor technology has been studied. Viscosity is the most important parameter of the oil's physical properties, which directly determines the performance of lubrication oil. Lubricating oil viscosity online measurements are mainly divided into capillary measurement [73], micro vibration measurement of [74], [75], quartz resonant acoustic shock measurement [76], [77] and magnetic measurement. Chemical properties of the lubricating oil will change as the physical properties change, such as conductive properties etc.. The physical and chemical properties of the lubricating oil may be caused by contaminants or transfer of the material itself. The main contaminant is water pollution, the main water contaminants measurements are the capacitance measurement [78-79], impedance measurement [80-81], and the transfer of the material is mainly reflected in the wear of materials. For wear measurements, in recent years the development of photoelectric sensors [82], photoelectric and magnetic sensors [83], mixed image and magnetic sensors [84](as shown in Fig 5.), induction sensor [85], sensors based on capacitance and impedance [86], sensors based on the energy principle [87], sensors based on ultrasonic principle [88]. 


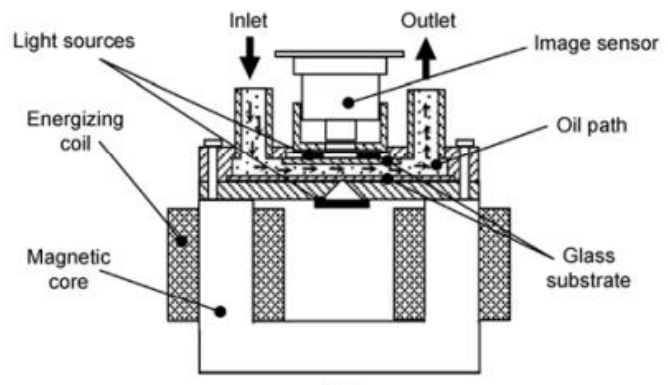

(a)

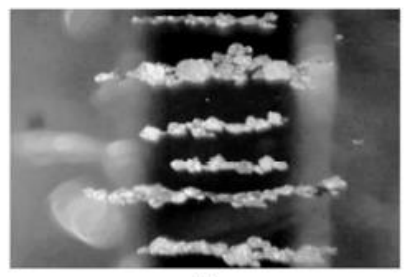

(b)

Fig 5. Principle of on-line wear debris imaging sensor[84]

In view of the development of the on-line condition monitoring sensor technology for lubricating oil, in addition to sensors of the physical and chemical properties of the lubricating oil and the sensors of wear debris, the sensors is also including such as Infrared (IR) and Fourier transform infrared (FTIR) spectrometry[89], XRF (X-ray fluorescence ) sensors[90]、 Photo-acoustic spectroscopy (PAS)[91] 、 Fluorescence spectroscopy[92] etc..

The wear state of the equipment, especially the key tribological system such as gear, engine and bearing are very important. A study from NASA reported[ 93] about oil analysis and vibration fusion systems to monitor the state showed that oil analysis is earlier to identify the wear compared with vibration, and can monitor the evolution of the wear process, which is also the oil analysis different with vibration and acoustic emission. Based on the consideration of the accuracy and reliability of on-line oil analysis monitoring technology, the development of it is expounded mainly from the view of wear particle analysis in this paper.

Studies have shown that the severity, wear rate, wear type and wear position of the fault have a certain relationship with wear particle characteristics. For example, particle size distribution and size can characterize the severity and form of wear, but the size and features cannot describe the wear mechanism and the reason why wear particle generates, therefore it is necessary to study other particle characteristics to describe the wear state roundly. Wear particle shape or contour recognition is more efficient to know about the wear mechanism, because they have their own typical characteristics, such as abrasive wear which is flake, cutting wear particles which is curled and so on. The formation of wear particles has a very close relationship with wear severity. For example, in the running-in wear stage, abrasive wear particles are more, and in the severe wear stage, the fatigue pitting wear particles are more. The wear debris features also include surface texture, edge features and color for condition monitoring and fault diagnosis of equipment [94]. And there are some achievements in fault diagnosis by using these features. Peng [95] used focused scanning electron microscopy of particles to extract wear particle surface morphology and topological structure features of six types particles, and the neural network, fuzzy and multilayer perceptron with the reverse learning rules are used for type identification. Test results showed that the neural network has a satisfying ability of classification. Chiou et al. [96] developed an on-line sensor to monitor the wear debris based on electromagnetic flow. The operation principle of the sensor is that wear particle induces magnetic current density to change, and the changes can lead the Holzer sensor output voltage changes. Test results showed that the voltage is a power function of wear debris counts. Therefore, this sensor has a certain application potential in the on-line wear particle analysis. Yan [97] introduced a kind of on-line wear monitoring system for marine diesel engine. The test results showed that the online detection system which is used to evaluate the working state of the diesel engine system is effective, the ferromagnetic particles only influenced by the magnetic field, gravity and other factors are negligible, and while low capacitance oil quality detector can better distinguish capacitance change due to moisture, metal particles etc. And with the help of the ferromagnetic particle detector and the lubricating oil quality detector, it can be more effective to distinguish the difference between ferromagnetic and non-ferromagnetic particles. Miller [98] adopted the on-line wear particle monitoring method to study status of aero engine. Test results showed that the 
on-line wear particle analysis is very effective for monitoring condition of rolling bearings, and the quality of wear debris or debris counts can effectively characterize the wear state, and found that it has large wear particles in bearing operation even in the early stage. The application of the aero engine proved the feasibility and application potential of the on-line wear particle analysis. Wu et al. [69] utilized the online ferrography for radial bearings for wear condition monitoring in different conditions, and used ICPA to evaluate the wear condition. Test results showed that the IPCA value accords with bathtub curve, and the main wear mechanisms are micro cutting and plough. Raadnui[99] developed a low cost oil condition monitoring sensor. The sensor is sensitive to wear particles, contaminants and so on. Experiments showed that when there is one of the magnetic particles, moisture and dust pollution, the output of the sensor is affected to $99 \%$; the output of the sensor changes to $75 \%$ when there are three kinds of pollution. Levi et al. [100] utilized direct reading ferrography analysis, atomic microscope and scanning electron microscope image analysis to research the Wankel engine failure. Test results showed that the analytical ferrography has a good effect in monitoring: the fault occurred in the early stage of six engines, and contact fatigue was found after disassembling of the engine needle bearing. The study is also applied to monitor the state of the Wankel engine, which has obtained a good result. Wu [101] used on-line ferrography to extract the IPCA and Large wear particle proportion, and vector data description supported was used to classify the wear condition of the engine. Test results showed that the two parameters and the algorithm can effectively identify the wear state, and it has a good application potential in on-line wear condition evaluation, especially in the whole life condition monitoring, as shown in Fig 6.

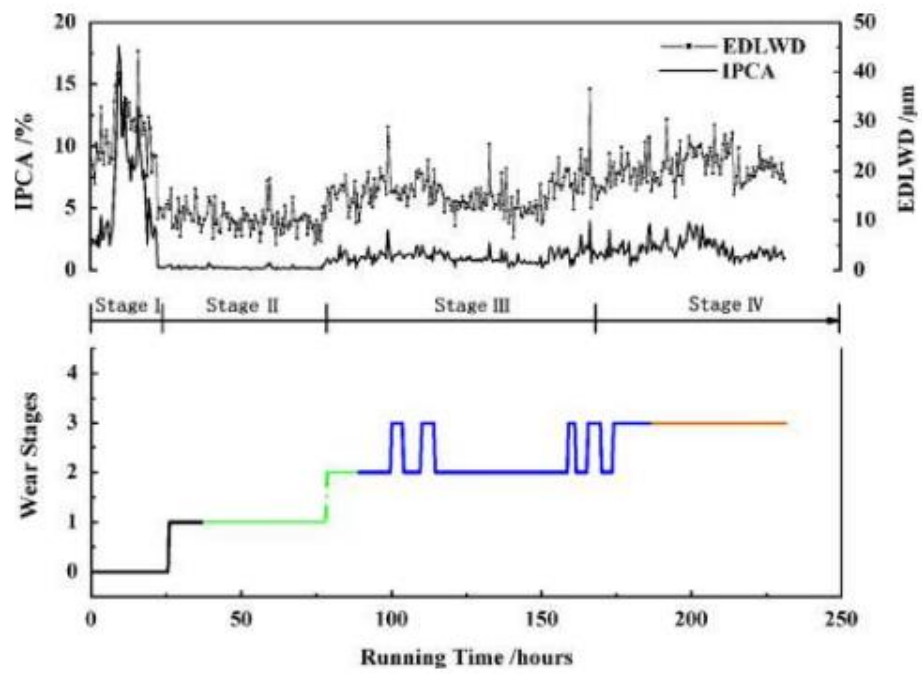

Fig 6. The stage evolution of wear states[101].

2.4 Other analytical techniques

For the industrial field, different detection techniques have developed to ensure the device operating safety. Except vibration, acoustic emission, oil analysis, the on-line condition monitoring technology also include temperature detection, ultrasonic detection, current signature motor detection, etc. Temperature detection is to measure whether the temperature is beyond the previous experience value to determine whether the bearing is defective. Temperature detection is not sensitive in the early stage of fault bearing, but it changed significantly in extreme conditions or failure, so temperature detection is less used alone of rolling bearing condition monitoring and fault diagnosis [102-104]. The bearing internal temperature field is complex, so the more current research is how to obtain the internal temperature field and how the temperature field affects the bearing performance [105-108]. Ultrasonic detection can also be used in bearing condition monitoring [109-110]. In recent years the ultrasonic detection applied to measure the oil film thickness of rolling bearing lubrication [111-113], in order to obtain the state of rolling bearing [114]. Current signature Motor detection in recent years has begun to apply to fault diagnosis of rolling bearings, which is mainly used in the deep buried of the centrifugal pump [115-116], nuclear reactor [117] and asynchronous motor drive [118-119], etc..

2.5 summary

The above monitoring technologies are currently the most widely used technology of rolling bearing monitoring technology. The characteristics of production equipment in modern industry are upsizing, complex, continuous, speedup and automation. The process of mechanical equipment fault diagnosis includes signal acquisition, signal processing, feature extraction, inference and conclusions. In the process, a sensor can just 
provide local information, which means we can obtain a one-sided information about the machinery and equipment, so the machinery and equipment need more comprehensive consideration to different parts to make the fault diagnosis accurate and effective; the single sensor signal will encounter noise and signal distortion. When the single sensor fails, the normal system will not work accurately, so the sensor signal uncertainty requires the use of the redundant and complementary information of multiple sensors to conduct a comprehensive analysis, then to reduce the inherent uncertainty of the single sensor system. The feature extracted from a single sensor signal also has the characteristics of a single sensor signal which is local, one-sided, and characteristic value error easily, which leads decision error. The inference will be provide based on the features extracted from the sensors signal, and each inference method has its own advantages, it also has its inherent shortcomings. To reduce and eliminate the uncertainty of each link of the fault diagnosis process which occurred by the shortcoming of inference mechanism, the multi-sensors fusion technology has been developed..

\section{Multi-sensors fusion technology}

Multi-sensors fusion is a multi-source information fusion, also called information fusion. It wasfirst proposed in 1970s, and military application gave the birth to the technology. At present, most researchers accept the definition of information fusion which is proposed by the Council of the United States armed forces laboratory JDL [120]: information fusion is a multistage process, including the multi-source data detection, combination and estimation, so as to improve the estimation precision of state and identity, and evaluate the importance of battle situation and threat completeness and in time. The information fusion technology we are studying is a simulation function of the human brain to deal with the complex problem. In the multi-sensor system, various sensors provide different characteristics which may be time-varying or time invariant, real-time or non-eal-time, deterministic or stochastic, precise or fuzzy, exclusive or complementary etc. Multi-sensor information fusion systems will make full use of multiple sensor resourcesthrough the reasonable controlling and using of all kinds of observation information in space and time to redundant and complementary information based on a combined optimization criterion, to obtain the consistency interpretation and description to observation environment and generate a new result at the same time. The goal is to separate the observation information based on a variety of sensors, then a combination of information is optimized to get more effective information. The ultimate aim is to use multiple sensors or joint operation advantages to promote the effectiveness of the whole system [121].

According to the abstraction level of data fusion, the information fusion can be divided into three levels: data fusion, feature fusion and decision fusion.

(1) Data fusion is the lowest fusion, which is directly fusing the sensor data. The feature extraction and the inference are done based on it. This model has an advantage with less loss of data that can provide a high precision, as Fig 7. shown.

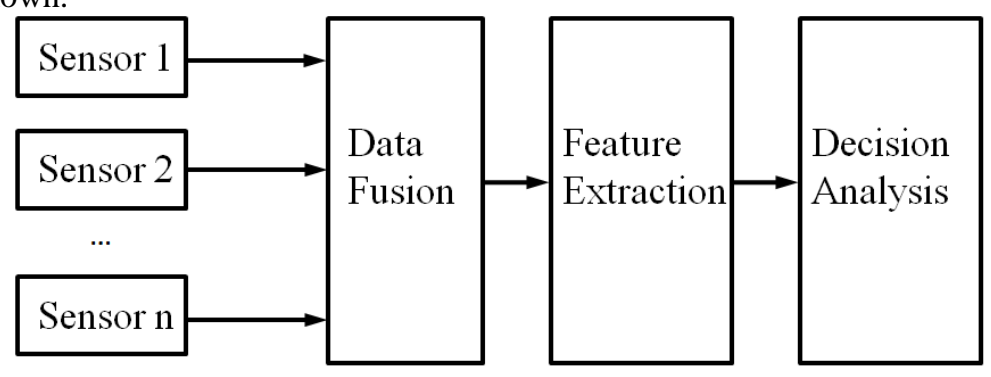

Fig 7. Structure of data fusion

Hansen et al. [122] used multi-sensor information fusion to monitor the gear and related system, and obtained the state of the mechanical parts and environment by filtering and signal processing of the data. Fang et al. [123] used a single sensor to evaluate the performance of the whole life of the mechanical equipment by using the multiple characteristic data of a single sensor in time series. Chen et al. [124] acquired and analyzed the data of the eleven types of failure of large rotating machinery. The phase and trajectory map of $\mathrm{X}$ and $\mathrm{Y}$ direction data were integrated to promote the development of fault diagnosis. Khan et al. [125] optimized the sensor's location to study how to reduce the redundant information of the fixture multi-sensor fusion fault diagnosis system, and got accurate diagnosis results by using the least sensor's data. Heger et al. [126] used eight IEEE1394 standard cameras to obtain the surface structure information of the same texture in different directions, and the image fusion greatly enhanced the effective information compared with the original image, but the data fusion process has a large amount of data and does not have error correction ability, and the sensors 
used need to belong to the same, so data fusion is not suitable for rolling bearing fault diagnosis system of online application.

(2) Feature fusion belongs to the middle level. The features are extracted from each sensor signal first, then the fusion is completed with the features. The advantages of the model are realizing considerable data compression to reduce the requirements of communication bandwidth, and the model is suitable for real-time processing, although it lost some useful information to make fusion decrease, as shown in Fig 8.

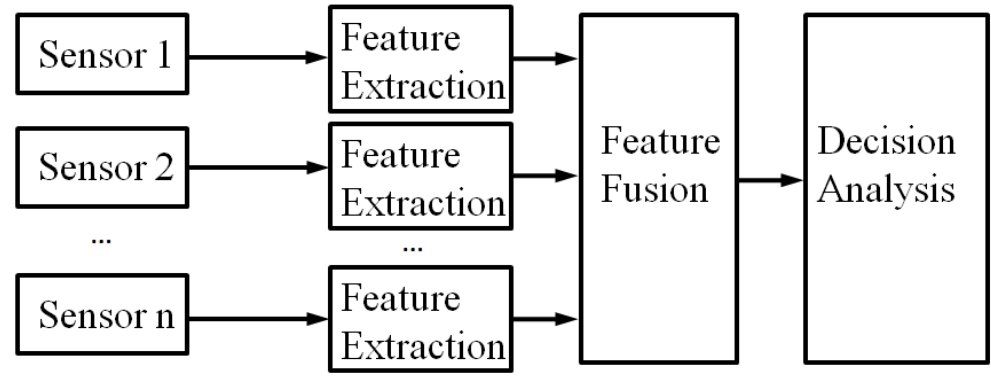

Fig 8. Structure of feature fusion

Feature fusion can be divided into two categories: target state fusion and target feature fusion. Target state fusion is mainly used in the field of multi target tracking. The common mathematical algorithms include Calman filter theory, joint probabilistic data association, multiple hypothesis method, interactive multi model method and sequential processing theory etc.. Target feature fusion belongs to the pattern recognition problem, and the common mathematical algorithms include parameter template method, feature compression and clustering method, artificial neural network, K order nearest neighbor method and so on.

(3) Decision fusion requires a high level of integration. Decisions are made by each sensor data first, then the local decisions finish fusion at the fusion center. The decision fusion is directed against the decision of specific objective, the fusion results directly affect the accuracy of decision-making. This approach lost the largest amount of data in the three kinds of approaches, but it uses the smallest amount of communication, has a strong anti-interference ability, an advantage of low cost, and is depending least on sensors, as shown in Fig 9.

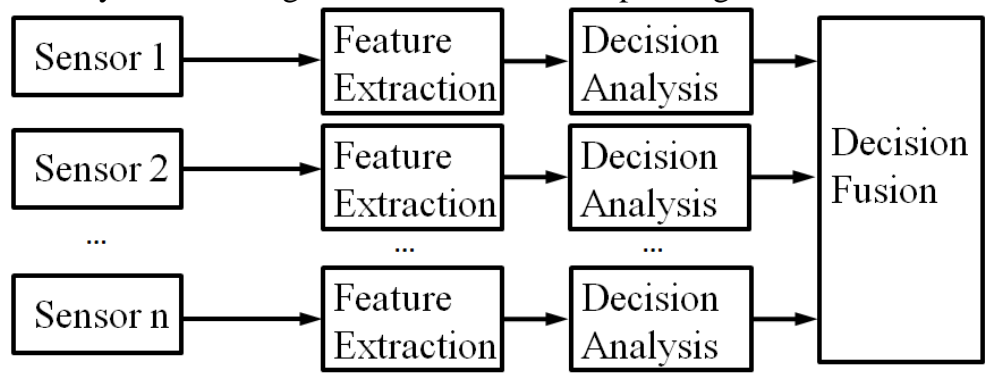

Fig 9. Structure of decision fusion

The common algorithms are Bayesian inference, expert system, D-S evidence theory, fuzzy theory, etc.

The information fusion technology in this paper will be introduced mainly from two aspects: the feature fusion technology and the decision fusion technology.

To obtain the relationship of cutting tool surface finish and the size deviation, Azouzi et al. [127] carried out the different cutting feed rate and cutting depth tests, and used neural network technology to analyze the statistics parameters which showed that the surface finish can evaluate the machining error under different processing conditions. Quan et al. [128] utilized the neural network to fuse the acoustic emission signal and the force signal to identify the machine tool online wear state. Results showed that it is an effective method for the real-time online monitoring tool. Peng et al. [129] utilized the vibration and wear debris analysis to monitor the state of the gearbox, the test results showed that single sensor technology has its own advantages. For example, wear debris analysis has an advantage in analyzing the wear trend and can obtain the wear mechanism earlier compared with vibration; vibration has a better performance in real-time and reliable response characteristics of bearing state, and the combination of the two methods can make the diagnosis more accurate. Then Peng et al. [130] also used the two methods to monitor the state of spur gear under overload and cyclic loading, the tests results showed that the vibration analysis has advantages in the characterization of gear fault, and the wear debris analysis has advantages in the identification of wear form. Akagaki et al.[131] did the 
wear test caused by oil pollution of the deep groove ball bearing (6002P5), and utilized wear debris analysis, spectral analysis and vibration to monitor the process. At the same time the friction pair surface was observed by scanning electron microscope. Test results showed that wear debris analysis and vibration are effective technologies to monitor the wear of the bearings. Dan et al. [132] adopted the reliability analysis based on the fault tree which is the extension of the fault tree analysis to improve the reliability of system. In 2009, Feng et al. [133] adopted the ferrography technology and vibration to characterize the fatigue pitting of gear process in time and frequency domain. Experimental results showed that when the crack initiated, crack expansion and pitting occurred, characteristic parameters of vibration had obvious change in time and frequency domain, size and the number of wear debris also showed an increasing trend, and wear debris analysis is more effective in analysis of wear mechanism compared with vibration. Gao et al. [134] used EMD and intrinsic mode functions to extract the vibration signal features to output the state of high pressure cylinder in the thermal power generation units. Test results showed that the comprehensive method has a higher accuracy of the feature extraction and identification of the fault. Chee Keong Tan [135] explored multi-sensor technology for the gearbox condition monitoring and fault diagnosis and found acoustic emission had a difficulty of application. Test results showed that acoustic emission is sensitive with the temperature of the lubrication oil and the surface finish of the friction pair. Then Chee Keong Tan et al. [136] carried out the test of fatigue wear of spur gears, and used acoustic emission, vibration, and oil spectrum analysis to analyze the state. Results showed that the features extracted from acoustic emission signals have a linear relationship with the test time and test torque, and they have a higher sensitivity under a high torque compared to the other two kinds of detection technology. T.H.Loutas [137] adopted the vibration, acoustic emission and oil particle counting to monitor the state of gear. Test results showed that the acoustic emission technique does not have advantages in normal wear period, but it is more sensitive than others when a crack initiated, as Fig. 10 shows.

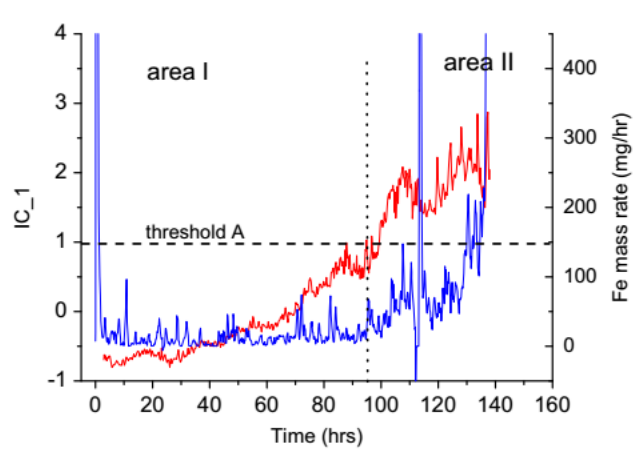

(a)

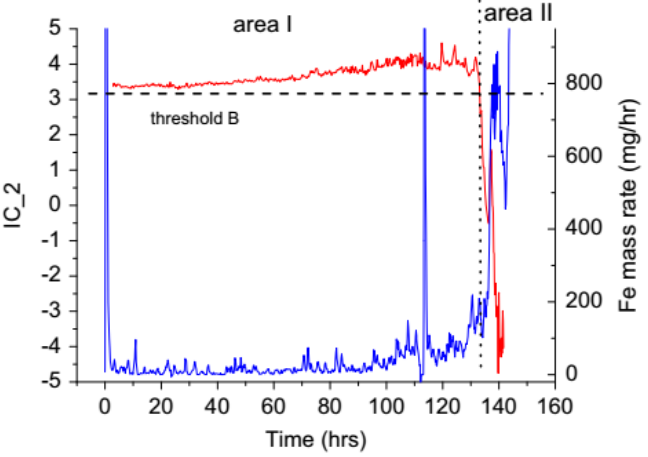

(b)

Fig 10. (a)the lower threshold of fusion. (b)the upper threshold of fusion[137].

$\mathrm{Li}$ et al. [138] utilized time and frequency domain amplitude of the vibration signal and geometric features of the on-line wear debris image to characterize the state of marine diesel engine. Test results showed that the accuracy of the on-line wear debris image analysis is not high under the current experimental conditions, but it can significantly improve the rate of correct diagnosis with the fusing the vibration signal. Also, online wear debris images can provide more information about the state of the marine diesel engine. In 2007, Gao et al. [139] used oil analysis and vibration to realize the condition monitoring and fault diagnosis of gear box. First, signal features were extracted from single detection technology, then D-S evidence theory was used to fuse features. Experimental results showed that the fusion technology has a higher reliability and applicability compared to the single detection technology. Ebersbach et al. [140] combined vibration with oil analysis and wear debris analysis to establish an expert system to realize the condition monitoring of rotating machinery. Tests results showed that the expert system has a higher reliability and universality compared to manual experience to judge the operation status of the machine. Yan et al. [141] developed a new remote online monitoring and fault diagnosis system for marine diesel engines. The online monitoring system is set up in the ship which used nine wear characteristics such as wear debris surface roughness, oil viscosity, moisture, IPCA, and the fault diagnosis system is set up in the laboratory. The test on the No. 2 of the Yangtze River ship shows that the remote fault diagnosis system has a good validity and reliability. Gabrijel et al. [142] used oil analysis and vibration to analyze the gear sliding wear state. The time series analysis method was used to reduce redundancy of oil information, K-mean clustering and k-nearest neighbors Classification were used to reduce the impact to results by the amplitude modulation of vibration in fault 
diagnosis. The results showed that the multi-sensors information fusion whose features is optimized based on oil characteristic and vibration characteristics of rolling bearing's inner race fault information is better than the effect of single sensor technology. To solve the problem of fault classification for bearings, first signal features were extracted, then principal component analysis method was used to reduce dimensionality of the signal characteristics, finally a fuzzy $\mathrm{C}$-means model was used to realize fault diagnosis. Test results show that the recognition effect is ideal [143]. Pavle et al. [143] evaluated the residual life of rolling bearing based on entropy extracted by Gauss model. The model has some advantages that does not require a priori knowledge, knowing the operating conditions, has the no limitation of statistical characteristics, and is sensitive of the early fault and so on,but it needs a large amount of calculation. The results need professional knowledge to determine the fault type, and the position and extent of failure are not clear. Zhang et al. [144] used the local projection method and hidden Markov model $[145,146,147]$ to evaluate the performance of the decay state of bearing. The local projection method [148] was used to reduce dimensionality of redundant information [149], and hidden Markov model was used to evaluate the decay state of the bearing [150]. The data used in the text including a total of five groups that three groups are samples, two groups [151] are applied to the assessment of the case. The result is not good which is led by fewer samples.

\section{Conclusion and Prospect}

As the key part of rotating machinery, rolling bearings have been widely used in aerospace, ship, machine tools and other important fields, and its reliability directly restricts the reliability of mechanical equipment. In the running time, the reliability of the rolling bearing directly determines the status of the rolling bearing at that time. Therefore, it is necessary to keep monitoring the condition of the rolling bearing to ensure the reliable operation of the mechanical equipment. At present there are a lot of technologies to detect the state of rolling bearings, such as vibration detection, acoustic emission detection, oil detection, temperature detection, ultrasonic detection, etc. Each physical detection technology has its own advantages and disadvantages because of the different detection principle, such as vibration monitoring is not easy to detect early fault of rolling; acoustic emission technology can overcome this shortcoming but is easy to interfere by background noise; oil detection can use in the whole life cycle effective but limited by oil itself; while the temperature detection and ultrasonic detection only used in specified conditions or auxiliary use, so multi-sensors information fusion is the trend of development of mechanical equipment condition monitoring for the future. However, there is no denying that there are still some deficiencies about the multi-sensors information fusion:

a) Limitations to the parameter application fusion, such as data fusion, feature fusion and decision fusion. It reflects the status of the rolling bearing in the time sequence. Although it can increase the accuracy of fault diagnosis, it will do nothing to improve the reliability of the rolling bearing itself. Multi-sensor information should explain the mechanism of the fault of rolling bearing in the future and feedback in the design stage to promote the reliability of the bearing.

b) Redundancy of multi sensing information. The performance decay of rolling bearings likes stage, so in a stage the performance of one physical detection technology is particularly prominent. Hence the dimensionality reduction also needs use in physical detection technologies, not only a detection technology.

The shortcomings of multi-sensors information fusion are not only affected by the lack of fusion, it is also affected by the limitations of the physical detection technology itself. The challenges of the future analysis of vibration and acoustic emission are: 1) noise removal; 2) feature resolution; 3) multi vibration sources interference; 4) the fault location and size; 5) mutation effect on the vibration; 6) the nonlinear and non-stationary signal processing etc. The challenges of oil analysis in future as follows: 1 ) online lubricating oil physicochemical performance index acquisition; 2) the non-Newtonian affect of the characteristics for the online evaluation of lubricant oil; 3) effect of lubricating oil properties to wear debris characteristics; 4) the three-dimensional features reconstruction; 5) the typical parts wear debris sample database establishment etc. Also, temperature detection, ultrasonic detection and the other detection technologies because of the limitations of its application will no longer be analyzed in this paper.

This paper is not a comprehensive review of the advantages and disadvantages and application of detection technology, but these advantages and disadvantages are summarized and challenges in future are obvious. For the authors, the purpose of the paper is to provide the necessary basis for the follow-up study of the fault diagnosis of rolling bearing and a foundational knowledge for researchers about rolling bearings. 


\section{Competing Interests}

The authors declare no conflict of interests

Acknowledgments: The research work was supported by the Natural Science Foundation of China (NSFC) under the grant no. 51675403 and no. 51275381 and National Research Foundation, South Africa (grant numbers: IFR160118156967 and RDYR160404161474).

\section{Reference}

1. Nandi S, Toliyat H A, Li X. Condition Monitoring and Fault Diagnosis of Electrical Motors-A Review[J]. IEEE Transactions on Energy Conversion, 2005, 20(4):719-729.

2. Li Junqing. Fault diagnosis technology of rolling bearing and its application in industry [D]. Zhengzhou University, 2010

3. Lu Feng. Study on fusion technology of aero engine fault diagnosis [D]. Nanjing University of Aeronautics \&amp; Astronautics, 2009

4. Zhang Ji. Research on sensor fault diagnosis method based on multi-source information fusion [D]. North China Electric Power University (Baoding), 2008

5. Harris, Kotiz Larset al. Rolling bearing analysis [M]. Machinery Industry Press, 2009

6. Spacek J. Maintenance strategies of power equipments with a brief view to condition monitoring of power transformers[C]// Modern Technique and Technologies, 2008. MTT 2008. International Conference. IEEE, 2008:16-19.

7. Huang L, Chen Y, Chen S, et al. Application of RCM analysis based predictive maintenance in nuclear power plants[C]// International Conference on Quality, Reliability, Risk, Maintenance, and Safety Engineering. 2012:1015-1021.

8. Lei yaguo. Hybrid intelligent technology and its application [D]. Xi'an Jiao Tong University in fault diagnosis, 2007

9. Sturm A, Kinsky D L D. Diagnostics of rolling-element bearing condition by means of vibration monitoring under operating conditions[J]. Measurement, 1984, 2(2):58-62.

10. Mechefske C K, Mathew J. Fault detection and diagnosis in low speed rolling element bearings Part I: The use of parametric spectra[J]. Mechanical Systems \& Signal Processing, 1992, 6(4):297-307.

11. Mechefske C K, Mathew J. Parametric spectral estimation to detect and diagnose faults in low speed rolling element bearings: Preliminary investigations[J]. Mechanical Systems \& Signal Processing, 1993, 7(1):1-12

12. Martin H R, Honarvar F. Application of statistical moments to bearing failure detection[J]. Applied Acoustics, 1995, 44(1):67-77.

13. Heng R B W, Nor M J M. Statistical analysis of sound and vibration signals for monitoring rolling element bearing condition[J]. Applied Acoustics, 1998, 53(1):211-226.

14. Mori K, Kasashima N, Yoshioka T, et al. Prediction of spalling on a ball bearing by applying the discrete wavelet transform to vibration signals[J]. Wear, 1996, 195(1-2):162-168.

15. Li C J, Wu S M. On-line severity assessment of bearing damage via defect sensitive resonance identification and matched filtering[J]. Mechanical Systems \& Signal Processing, 1988, 2(3):291-303.

16. Dron J P, Rasolofondraibe L, Bolaers F, et al. High-resolution methods in vibratory analysis: application to ball bearing monitoring and production machine[J]. International Journal of Solids \& Structures, 2001, 38(2425):4293-4313.

17. Liu B, Ling S F, Gribonval R. Bearing failure detection using matching pursuit[J]. Ndt \& E International, 2002, 35(4):255-262.

18. Samanta B, Al-Balushi K R. ARTIFICIAL NEURAL NETWORK BASED FAULT DIAGNOSTICS OF ROLLING ELEMENT BEARINGS USING TIME-DOMAIN FEATURES[J]. Mechanical Systems \& Signal Processing, 2003, 17(2):317-328 
19. Lou X, Loparo K A. Bearing fault diagnosis based on wavelet transform and fuzzy inference[J]. Mechanical Systems \& Signal Processing, 2004, 18(5):1077-1095.

20. Kar C, Mohanty A R. Application of KS test in ball bearing fault diagnosis[J]. Journal of Sound \& Vibration, 2004, 269(1-2):439-454.

21. Purushotham V, Narayanan S, Prasad S A N. Multi-fault diagnosis of rolling bearing elements using wavelet analysis and hidden Markov model based fault recognition[J]. Ndt \& E International, 2005, 38(8):654-664.

22. Randall R B. Detection and diagnosis of incipient bearing failure in helicopter gearboxes[J]. Engineering Failure Analysis, 2004, 11(2):177-190.

23. Sawalhi N, Randall R B. Simulating gear and bearing interactions in the presence of faults : Part I. The combined gear bearing dynamic model and the simulation of localised bearing faults[J]. Mechanical Systems \& Signal Processing, 2008, 22(22):1924-1951.

24. Sawalhi N, Randall R B. Simulating gear and bearing interactions in the presence of faults : Part II: Simulation of the vibrations produced by extended bearing faults[J]. Mechanical Systems \& Signal Processing, 2008, 22(8):1952-1966.

25. Cheng J, Yu D, Yang Y. A fault diagnosis approach for roller bearings based on EMD method and AR model[J]. Mechanical Systems \& Signal Processing, 2006, 20(2):350-362.

26. Hao R, Chu F. Morphological undecimated wavelet decomposition for fault diagnostics of rolling element bearings[J]. Journal of Sound \& Vibration, 2009, 320(4):1164-1177.

27. Zhang S, Mathew J, Ma L, et al. Best basis-based intelligent machine fault diagnosis[J]. Mechanical Systems \& Signal Processing, 2005, 19(2):357-370.

28. Khemili I, Chouchane M. Detection of rolling element bearing defects by adaptive filtering[J]. European Journal of Mechanics - A/Solids, 2005, 24(2):293-303.

29. Abbasion S, Rafsanjani A, Farshidianfar A, et al. Rolling element bearings multi-fault classification based on the wavelet denoising and support vector machine[J]. Mechanical Systems \& Signal Processing, 2007, 21(7):2933-2945.

30. Yuan J, He Z, Zi Y, et al. Adaptive multiwavelets via two-scale similarity transforms for rotating machinery fault diagnosis[J]. Mechanical Systems \& Signal Processing, 2009, 23(5):1490-1508.

31. Wang Y, He Z, Zi Y. Enhancement of signal denoising and multiple fault signatures detecting in rotating machinery using dual-tree complex wavelet transform[J]. Mechanical Systems \& Signal Processing, 2010, 24(1):119-137.

32. Wang G, Luo Z, Qin X, et al. Fault identification and classification of rolling element bearing based on time-varying autoregressive spectrum[J]. Mechanical Systems \& Signal Processing, 2008, 22(4):934-947.

33. Wang W, Li Q, Zhao G. Novel approach based on chaotic oscillator for machinery fault diagnosis[J]. Measurement, 2008, 41(8):904-911.

34. Hong H, Liang M. Fault severity assessment for rolling element bearings using the Lempel-Ziv complexity and continuous wavelet transform[J]. Journal of Sound \& Vibration, 2009, 320(1-2):452-468.

35. Lei Y, Lin J, He Z, et al. Application of an improved kurtogram method for fault diagnosis of rolling element bearings[J]. Mechanical Systems \& Signal Processing, 2011, 25(5):1738-1749.

36. Zhou Y, Chen J, Dong G M, et al. Application of the horizontal slice of cyclic bispectrum in rolling element bearings diagnosis[J]. Mechanical Systems \& Signal Processing, 2012, 26(1):229-243.

37. Wang X, Zi Y, He Z. Multiwavelet denoising with improved neighboring coefficients for application on rolling bearing fault diagnosis[J]. Mechanical Systems \& Signal Processing, 2011, 25(1):285-304.

38. Lei Y, Lin J, He Z, et al. A review on empirical mode decomposition in fault diagnosis of rotating machinery[J]. Mechanical Systems \& Signal Processing, 2013, 35(1-2):108-126.

39. Wang J, Xu G, Zhang Q, et al. Application of improved morphological filter to the extraction of impulsive attenuation signals[J]. Mechanical Systems \& Signal Processing, 2009, 23(1):236-245.

40. Cui L, Wu N, Ma C, et al. Quantitative fault analysis of roller bearings based on a novel matching pursuit method with a new step-impulse dictionary[J]. Mechanical Systems \& Signal Processing, 2016, 68.

41. Wang T, Liang M, Li J, et al. Bearing fault diagnosis under unknown variable speed via gear noise cancellation and rotational order sideband identification[J]. Mechanical Systems \& Signal Processing, 2015, s 62-63:30-53.

42. Li B, Zhang P L, Liu D S, et al. Feature extraction for rolling element bearing fault diagnosis utilizing generalized S transform and two-dimensional non-negative matrix factorization[J]. Journal of Sound \& Vibration, 2011, 330(10):2388-2399.

43. Borghesani P, Pennacchi P, Randall R B, et al. Application of cepstrum pre-whitening for the diagnosis of bearing faults under variable speed conditions[J]. Mechanical Systems \& Signal Processing, 2013, 36(2):370-384.

44. Rai A, Upadhyay S H. A review on signal processing techniques utilized in the fault diagnosis of rolling element bearings[J]. Tribology International, 2016, 96:289-306. 
45. Balerston, H.L. The detection of incipient failure in bearings, Materials Evaluation, 1969,27:121-128.

46. Yoshioka T, Fujiwara T. A new acoustic emission source locating system for the study of rolling contact fatigue[J]. Wear, 1982, 81(1):183-186.

47. Catlin Jr. J.B. The use of ultrasonic diagnostic technique to detect rolling element bearing defects. Proceeding of machinery and vibration monitoring and analysis meeting ,vibration institute, USA,April 1983,123-130.

48. Holroyd T J, Randall N. Use of acoustic emission for machine condition monitoring British Journal of Non-Destructive Testong, Vol. 35, No.2, pp. 75-78 (Feb. 1993)[J]. Ndt \& E International, 1994, 27:210-210.

49. Bagnoli, S., Capitani, R., Citti, P. comparison of accelerometer and acoustic emission signals as diagnostic tools in assessing bearing, proceedings of $2^{\text {nd }}$ international conference on condition monitoring, London, UK, 1988,5,117-125.

50. Bansal V, Gupta B C, Prakash A, et al. Quality inspection of rolling element bearing using acoustic emission technique Journal of Acoustic Emission, Vol. 9, No. 2, pp. 142-146 (1990)[J]. Ndt \& E International, 1994, 27(4):216-216.

51. Shiroishi J, Li Y, Liang S, et al. BEARING CONDITION DIAGNOSTICS VIA VIBRATION AND ACOUSTIC EMISSION MEASUREMENTS[J]. Mechanical Systems \& Signal Processing, 1997, 11(5):693-705.

52. Yoshioka $\mathrm{T}$, Korenaga A, Mano $\mathrm{H}$, et al. Diagnosis of Rolling Bearing by Measuring Time Interval of $\mathrm{AE}$ Generation[J]. Journal of Tribology, 1999, 121(3):468-472.

53. Morhain A, Mba D. Bearing defect diagnosis and acoustic emission[J]. ARCHIVE Proceedings of the Institution of Mechanical Engineers Part J Journal of Engineering Tribology 1994-1996 (vols 208-210), 2003, 217(4):257-272.

54. Choudhury A, Tandon N. Application of acoustic emission technique for the detection of defects in rolling element bearings[J]. Tribology International, 2000, 33(1):39-45.

55. Guo Y B, Schwach D W. An experimental investigation of white layer on rolling contact fatigue using acoustic emission technique[J]. International Journal of Fatigue, 2005, 27(9):1051-1061.

56. Al-Ghamd A M, Mba D. A comparative experimental study on the use of acoustic emission and vibration analysis for bearing defect identification and estimation of defect size[J]. Mechanical Systems \& Signal Processing, 2006, 20(7):1537-1571.

57. Y. Li, S. Billington, C. Zhang, et al. Dynamic Prognostic Prediction of Defect Propagation on Rolling Element Bearings[J]. Tribology Transactions, 2008, 42(2):385-392.

58. Elforjani M, Mba D. Detecting natural crack initiation and growth in slow speed shafts with the Acoustic Emission technology[J]. Engineering Failure Analysis, 2009, 16(7):2121-2129.

59. Eftekharnejad, Babak. Condition monitoring of gearboxes using acoustic emission[J]. Cranfield University, 2010.

60. Kilundu B, Chiementin X, Duez J, et al. Cyclostationarity of Acoustic Emissions (AE) for monitoring bearing defects[J]. Mechanical Systems \& Signal Processing, 2011, 25(6):2061-2072.

61. Gu D S, Kim J G, An Y S, et al. Detection of faults in gearboxes using acoustic emission signal[J]. Journal of Mechanical Science \& Technology, 2011, 25(5):1279-1286.

62. Elforjani M, Mba D, Muhammad A, et al. Condition monitoring of worm gears[J]. Applied Acoustics, 2012, 73(8):859-863

63. Lu W, Jiang $\mathrm{W}, \mathrm{Wu} \mathrm{H}$, et al. A fault diagnosis scheme of rolling element bearing based on near-field acoustic holography and gray level co-occurrence matrix[J]. Journal of Sound \& Vibration, 2012, 331(15):3663-3674.

64. Wang J, He Q, Kong F. A new synthetic detection technique for trackside acoustic identification of railroad roller bearing defects[J]. Applied Acoustics, 2014, 85(6):69-81.

65. Elasha F, Mba D. Vibration and Acoustics Emissions analysis of Helicopter Gearbox, A comparative study[C]// International Conference on Reliability, Safety and Hazard. 2015.

66. Sadegh H, Mehdi A N, Mehdi A. Classification of acoustic emission signals generated from journal bearing at different lubrication conditions based on wavelet analysis in combination with artificial neural network and genetic algorithm[J]. Tribology International, 2015, 1(1):23-32.

67. Hase A, Mishina H, Wada M. Fundamental Study on Early Detection of Seizure in Journal Bearing by Using Acoustic Emission Technique[J]. Wear, 2015, 346:132-139.

68. Tonghai W U, Hongkun W U, Ying D U, et al. Progress and trend of sensor technology for on-line oil monitoring[J]. Science China Technological Sciences, 2013, 56(12):2914-2926.

69. Tonghai Wu, Junhong Mao, Guangneng Dong, et al. Journal Bearing Wear Monitoring via On-Line Visual Ferrography. Advanced Materials Research, 2010, 44-46:189-194.

70. Elnasharty I Y, Kassem A K, Sabsabi M, et al. Diagnosis of lubricating oil by evaluating cyanide and carbon molecular emission lines in laser induced breakdown spectra[J]. Spectrochimica Acta Part B Atomic Spectroscopy, 2011, 66(8):588-593. 
71. [Idros M F M, Ali S, Islam M S. Condition based engine oil degradation monitoring system, synthesis and realization on ASIC[C]// IEEE International Conference on Semiconductor Electronics. IEEE, 2014:9548-53.

72. Elżbieta Beran. Effect of chemical structure on the hydrolytic stability of lubricating base oils[J]. Tribology International, 2010, 43(12):2372-2377.

73. Agoston A, Ötsch C, Jakoby B. Viscosity sensors for engine oil condition monitoring-Application and interpretation of results[J]. Sensors \& Actuators A Physical, 2005, 121(2):327-332.

74. Markova L V, Myshkin N K, Kong H, et al. On-line acoustic viscometry in oil condition monitoring[J]. Tribology International, 2011, 44(9):963-970.

75. Markova L V, Myshkin N K, Kong H, et al. On-line acoustic viscometry in oil condition monitoring[J]. Tribology International, 2011, 44(9):963-970.

76. Durdag K. Solid state acoustic wave sensors for real-time in-line measurement of oil viscosity[J]. Sensor Review, 2008, 28(1):68-73.

77. Stoyanov P G, Grimes C A. A remote query magnetostrictive viscosity sensor.[J]. Sensors \& Actuators A Physical, 2000, 80(1):8-14.

78. Raadnui S, Kleesuwan S. Low-cost condition monitoring sensor for used oil analysis[J]. Wear, 2005, 259(7):1502-1506.

79. Shi-Yong M A. Development and application of a radio-frequency capacitive sensor[J]. Journal of Transducer Technology, 2001.

80. Turner J D, Austin L. Electrical techniques for monitoring the condition of lubrication oil[J]. Measurement Science \& Technology, 2003, 186(14):1051-1061.

81. Smiechowski M F, Lvovich V F. Electrochemical monitoring of water-surfactant interactions in industrial lubricants[J]. Journal of Electroanalytical Chemistry, 2002, 534(2):171-180.

82. [Kwon O K, Kong H S, Han H G, et al. On-line measurement of contaminant level in lubricating oil: US, US 6151108 A[P]. 2000.

83. Kuo W F, Chiou Y C, Lee R T. Fundamental characteristics of wear particle deposition measurement by an improved on-line ferrographic analyzer[J]. Wear, 1997, 208(1-2):42-49.

84. Mao J H. A New On-Line Visual Ferrograph[J]. Tribology Transactions, 2009, 52(5):623-631.

85. Han L, Hong W, Wang S. The Key Points of Inductive Wear Debris Sensor[C]// International Conference on Fluid Power and Mechatronics. 2011:809-815.

86. Powrie H. Use of electrostatic technology for aero engine oil system monitoring[C]// Aerospace Conference Proceedings. IEEE, 2000:57-72 vol.6.

87. Brown N K, Friedersdorf F J. Systems and methods to detect particulate debris in a fluid: US, US 8474305 B2[P]. 2013.

88. Edmonds J, Resner M S, Shkarlet K. Detection of precursor wear debris in lubrication systems[C]// 2000:73-77 vol.6.

89. Adams M J, Romeo M J, Rawson P. FTIR analysis and monitoring of synthetic aviation engine oils[J]. Talanta, 2007, 73(4):629-34.

90. Voort F R V D, Sedman J, Pinchuk D. An Overview of Progress and New Developments in FTIR Lubricant Condition Monitoring Methodology[J]. Journal of Astm International, 2011, 8(5):1-14.

91. Koskinen V, Fonsen J, Kauppinen J, et al. Extremely sensitive trace gas analysis with modern photoacoustic spectroscopy[J]. Vibrational Spectroscopy, 2006, 42(2):239-242.

92. Becker A. Application of an X-ray Fluorescence Instrument to Helicopter Wear Debris Analysis[J]. African Journal of Biotechnology, 2008, 7(20):3550-3553.

93. Dempsey P J. A Comparison of Vibration and Oil Debris Gear Damage Detection Methods Applied to Pitting Damage. 2000[J]. NASA Glenn Research Center.

94. Yuan Chengqing. Study on the characteristics of wear surface and wear surface and their relation to the wear process [D]. Wuhan University of Technology, 2005

95. Peng Z, Kirk T B. Automatic wear-particle classification using neural networks[J]. Tribology Letters, 1998, 5(4):249-257.

96. Chiou Y C, Lee R T, Tsai C Y. An on-line Hall-effect device for monitoring wear particle in oils[J]. Wear, 1998, 223(1-2):44-49.

97. Yan L, Zhong L, Xie Y, et al. Research on an on-line wear condition monitoring system for marine diesel engine[J]. Tribology International, 2000, 33(12):829-835.

98. Miller J L, Kitaljevich D. In-line oil debris monitor for aircraft engine condition assessment[J]. IEEE Aerospace Conference Proceedings, 2000, 6:49-56. 
99. Raadnui S, Kleesuwan S. Low-cost condition monitoring sensor for used oil analysis[J]. Wear, 2005, 259(7):1502-1506.

100. Levi O, Eliaz N. Failure Analysis and Condition Monitoring of an Open-Loop Oil System Using Ferrography[J]. Tribology Letters, 2009, 36(1):17-29.

101. Wu T, Peng Y, Wu H, et al. Full-life dynamic identification of wear state based on on-line wear debris image features[J]. Mechanical Systems \& Signal Processing, 2014, 42(s 1-2):404-414.

102. Mei Hongbin. Microcomputer monitoring and diagnosis system for bearing test machine of high speed railway vehicle [J]. Journal of Huazhong University of Science and Technology, 1994 (7): 22-27.

103. Tian Zhenhua, Wang Zhuo, Ma Chunyan. Rolling bearing condition monitoring system [J]. Journal of Changchun University of Technology, 2001, 22 (4): 8-10.

104. Ning Lian, Zhou Jiemin. Temperature condition monitoring technology for rolling bearings [J]. bearing, 2007 (2): 25-27.

105. Tala-Ighil N, Fillon M. A numerical investigation of both thermal and texturing surface effects on the journal bearings static characteristics[J]. Tribology International, 2015, 90:228-239.

106. Yan K, Wang N, Zhai Q, et al. Theoretical and experimental investigation on the thermal characteristics of double-row tapered roller bearings of high speed locomotive[J]. International Journal of Heat \& Mass Transfer, 2015, 84:1119-1130.

107. Yan K, Wang Y, Zhu Y, et al. Investigation on heat dissipation characteristic of ball bearing cage and inside cavity at ultra high rotation speed[J]. Tribology International, 2015, 93:470-481.

108. Yan K, Hong J, Zhang J, et al. Thermal-deformation coupling in thermal network for transient analysis of spindle-bearing system[J]. International Journal of Thermal Sciences, 2016, 104:1-12.

109. Kim Y H, Tan A C C, Mathew J, et al. Condition Monitoring of Low Speed Bearings: A Comparative Study of the Ultrasound Technique Versus Vibration Measurements[M]// Engineering Asset Management. Springer London, 2008:182-191.

110. Lineham J. Ultrasonic probes for inspecting bearings[J]. World Pumps, 2008, 2008(503):34-36.

111. Schirru M M, Dwyer-Joyce R S. A model for the reflection of shear ultrasonic waves at a thin liquid film and its application to viscometry in a journal bearing[J]. ARCHIVE Proceedings of the Institution of Mechanical Engineers Part J Journal of Engineering Tribology 1994-1996 (vols 208-210), 2015, 230.

112. Drinkwater B W, Zhang J, Kirk K J, et al. Ultrasonic Measurement of Rolling Bearing Lubrication Using Piezoelectric Thin Films[J]. Journal of Tribology, 2009, 131(1).

113. Zhang K, Meng Q, Chen W, et al. Ultrasonic measurement of oil film thickness between the roller and the inner raceway in a roller bearing[J]. Industrial Lubrication \& Tribology, 2015, 67(6).

114. Zhihe Duan, Tonghai Wu, Yuelei Zhang,et al. Design of an aircraft rolling bearings platform and its thermal performance evaluation. Tehnicki Vjesnik-Technical Gazette, 2016. (Accepted)

115. Hernandezsolis A, Carlsson F. Diagnosis of Submersible Centrifugal Pumps: A Motor Current and Power Signature Approaches[J]. Epe Journal European Power Electronics \& Drives, 2015, 20(1):58-64.

116. Mohanty A R 1. Fault detection in a centrifugal pump using vibration and motor current signature analysis[J]. International Journal of Automation \& Control, 2012, 6(3/4):261-276.

117. Ma J, Wang S, Zhao M, et al. Therapeutic potential of cladribine in combination with STAT3 inhibitor against multiple myeloma[J]. Bmc Cancer, 2011, 11(18):: 255.

118. Hegde V, Maruthi G S. Experimental investigation on detection of air gap eccentricity in induction motors by current and vibration signature analysis using non-invasive sensors[J]. Energy Procedia, 2012, 14(4):1047-1052.

119. Pires V F, Kadivonga M, Martins J F, et al. Motor square current signature analysis for induction motor rotor diagnosis[J]. Measurement, 2013, 46(2):942-948.

120. Wald L. Some terms of reference in data fusion[J]. IEEE Transactions on Geoscience \& Remote Sensing, 1999, 37(3):1190-1193.

121. Liu Q, Wang H P. A case study on multisensor data fusion for imbalance diagnosis of rotating machinery[J]. Artificial Intelligence for Engineering Design Analysis \& Manufacturing, 2001, 15(3):203-210.

122. Hansen R J, Hall D L, Kurtz S K. New approach to the challenge of machinery prognostics[J]. Journal of Engineering for Gas Turbines \& Power, 1995, 117(2):320-325.

123. Fang X D, Yao Y L. In-process Evaluation of the Overall Machining Performance in Finish-Turning via Single Data Source[J]. Journal of Manufacturing Science \& Engineering, 1997, 119(3):444-447.

124. Chen Y, Orady E. An Entropy-Based Index Evaluation Scheme for Multiple Sensor Fusion in Classification Process[J]. Journal of Manufacturing Science \& Engineering, 1999, 121(4):727-732. 
125. Khan A, Ceglarek D, Shi J, et al. Sensor Optimization for Fault Diagnosis in Single Fixture Systems: A Methodology[J]. Journal of Manufacturing Science \& Engineering, 1999, 121(1):109-117.

126. Heger A T, Pandit M C. Optical wear assessment system for grinding tools.[J]. Proc Spie, 2004, 13(13):450-461.

127. Azouzi R, Guillot M. On-line prediction of surface finish and dimensional deviation in turning using neural network based sensor fusion[J]. International Journal of Machine Tools \& Manufacture, 1997, 37(9):1201-1217.

128. Quan Y, Zhou M, Luo Z. On-line robust identification of tool-wear via multi-sensor neural-network fusion[J]. Engineering Applications of Artificial Intelligence, 1998, 11(6):717-722.

129. Peng Z. An integrated intelligence system for wear debris analysis[J]. Wear, 2002, 252(9):730-743.

130. Peng Z, Kessissoglou N J, Cox M. A study of the effect of contaminant particles in lubricants using wear debris and vibration condition monitoring techniques[J]. Wear, 2005, 258(11-12):1651-1662.

131. Akagaki T, Nakamura M, Monzen T, et al. Analysis of the Behaviour of Rolling Bearings in Contaminated Oil Using Some Condition Monitoring Techniques[J]. ARCHIVE Proceedings of the Institution of Mechanical Engineers Part J Journal of Engineering Tribology 1994-1996 (vols 208-210), 2006, 220(5):447-453.

132. Dan M S, Tiran J. Condition-based fault tree analysis (CBFTA): A new method for improved fault tree analysis (FTA), reliability and safety calculations[J]. Reliability Engineering \& System Safety, 2007, 92(9):1231-1241.

133. Feng W, Xie X, Cao Y. Study on Fault Diagnosis of Gear with Spall Using Ferrography and Vibration Analysis[C]// International Conference on Measuring Technology and Mechatronics Automation. IEEE, 2009:723-727.

134. Tan C K, Mba D. Identification of the acoustic emission source during a comparative study on diagnosis of a spur gearbox[J]. Tribology International, 2005, 38(5): 469-480.

135. Tan C K, Irving P, Mba D. A comparative experimental study on the diagnostic and prognostic capabilities of acoustics emission, vibration and spectrometric oil analysis for spur gears[J]. Mechanical Systems and Signal Processing, 2007, 21(1): 208-233.

136. Loutas T H, Roulias D, Pauly E, et al. The combined use of vibration, acoustic emission and oil debris on-line monitoring towards a more effective condition monitoring of rotating machinery[J]. Mechanical systems and signal processing, 2011, 25(4): 1339-1352.

137. Li Z, Yan X. Study on data fusion of multi-dimensional sensors for health monitoring of rolling bearings[J]. Insight-Non-Destructive Testing and Condition Monitoring, 2013, 55(3): 147-151.

138. Gao J, Zhang P, Liu B, et al. An Integrated Fault Diagnosis Method of Gearboxes Using Oil Analysis and Vibration Analysis[C]// International Conference on Electronic Measurement and Instruments. IEEE, 2007:1348-1353.

139. Ebersbach S, Peng Z, Yuan C, et al. Machine Condition Monitoring and Remaining Life Prediction Using Integrated Approach[M]// Advanced Tribology. Springer Berlin Heidelberg, 2009:949-956.

140. Yan X, Li Z, Yuan C, et al. On-line Condition Monitoring and Remote Fault Diagnosis for Marine Diesel Engines Using Tribological Information[J]. Chemical Engineering, 2013, 33:805-810.

141. MeriñoGergichevich, Cristian, Ondrasek, et al. Comparative study of methodologies to determine antioxidant capacity in Al-toxified blueberry amended with calcium sulphate[J]. Journal of Soil Science \& Plant Nutrition, 2014.

142. Wang F, Sun J, Yan D, et al. A Feature Extraction Method for Fault Classification of Rolling Bearing based on PCA[C]//Journal of Physics: Conference Series. IOP Publishing, 2015, 628(1): 012079.

143. Pavle Boškoski, Matej Gašperin, Dejan Petelin, et al. Bearing fault prognostics using Rényi entropy based features and Gaussian process models[J]. Mechanical Systemsls\&lssignal Processing, 2015, s 52-53:327-337.

144. Zhang S, Zhang Y, Li L, et al. Rolling Elements Bearings Degradation Indicator Based on Continuous Hidden Markov Model[J]. Journal of Failure Analysis \& Prevention, 2015, 15(5):691-696.

145. R. Malekian, Alain Kavishe, B.T. Maharaj, P. Gupta, G. Singh, H. Waschefort, "Smart vehicle navigation system using Hidden Markov Model and RFID Technology“, Wireless Personal Communications, Springer, Vol. 90, issue, 4, pp. 1717-1742, 2016

146. Zhongqin Wang, Ning Ye, Ruchuan Wang, Peng Li,"TMicroscope: Behavior Perception Based on the Slightest RFID Tag Motion", Elektronika ir Elektrotechnika, Vol.22, No.2, pp.114-122, 2016.

147. Zhongqin Wang, Ning Ye, Fu Xiao, Ruchuan Wang, "TrackT: Accurate Tracking of RFID Tags with mm-level Accuracy Using first-order Taylor series approximation", AD Hoc Networks, Elsevier, Vol.53, pp.132-144, 2016

148. Xiangjun Jin, Jie Shao, Xin Zhang, Wenwei An, "Modeling of nonlinear system based on deep learning framework", Nonlinear Dynamics, Springer, Vol.84, No. 3, pp.1327-1340, 2016

149. M. Reza, Dijana Capeska Bogatinoska, Aleksandar Karadimce, Jasna Trengoska, William A. Nyako, "A Novel Smart ECO model for Energy Consumption Optimization", 2015, Elektronika ir Elektrotechnika, Vol. 21, No.6, pp.75-80, 2015 
150. Xuefeng Li, Shibo Wang, Shangqing Hao, Zhixiong Li, "Numerical Simulation of Rock Breakage Modes under Confining Pressures in the Rock Cutting Process: an Experimental Investigation, IEEE Access, Vol.4, pp.5710-5720, 2016.

151. Tianhe Gong, Haiping Huang, Ping Chen, Tao Chen, "Secure Two-party Distance Computation Protocol Based on Privacy Homomorphism and Scalar Product in Wireless Sensor Networks", Tsinghua Science and Technology (IEEE), Vol.21, No.4, pp. 385-396, 2016. 